\title{
O turismo sobe o morro do Vidigal (Rio de Janeiro, Brasil): uma análise exploratória
}

\section{Tourism in Morro do Vidigal (Rio de Janeiro, Brasil): an exploratory analyzes}

\author{
Irma Miranda (MIRANDA, I.) ${ }^{*} \mathrm{e}$ \\ Rafael Ângelo Fortunato (FORTUNATO, A. R.) ${ }^{* *}$
}

RESUMO - As favelas fazem parte do circuito turístico do Rio de Janeiro (Brasil). Antes vistas como lugar de pobreza e perigoso, começam a ser percebidas como atrativo turístico. Para este artigo se analisou o turismo no morro do Vidigal de uma forma exploratória, ou seja, se apresenta um panorama do turismo na localidade sem um aprofundamento sobre temas específicos. O objetivo é mostrar as transformações ocorridas no Vidigal depois do aumento e consolidação da atividade turística na localidade. Trabalhou-se com a observação participante e entrevistas semiestruturadas com moradores e turistas, partindo da seguinte questão orientadora: o que você pensa sobre o turismo no Vidigal? Destaca-se, como resultado desta pesquisa exploratória, a organização de fóruns populares, a construção de pousadas comunitárias, a questão da contribuição do turismo para os moradores de favelas e reflexões sobre as possibilidades do turismo baseado na solidariedade minimizar os problemas do processo da gentrificação e promover o desenvolvimento a partir dos valores locais.

Palavras-chave: Turismo; Favelas; Vidigal; Transformação.

ABSTRACT - Rio's favelas are already part of the tourist circuit of Rio de Janeiro (Brazil). Previously considered a dangerous site, it starts being perceived as a tourism attraction. This paper examines tourism in Morro do Vidigal in an exploratory manner, i.e., it presents an overview of tourism in the site without going deeper into specific topics. The participating observation was part of the work, together with semi-structured interviews with locals and tourists. The guiding question for the analysis was: what do you think about tourism in Vidigal? Some of the issues that stand out in the result of this exploratory research are the organization of popular forums, building of community hostels, the question whether tourism does or does not bring benefits to the slum dwellers, and reflections about the possibilities solidarity tourism can minimize problems related to the gentrification process and promote the development based on local values.

Key words: Tourism; Favelas; Vidigal; Resear.

\footnotetext{
* Formação: Graduação em Turismo (bacharelado) pela Universidade do Estado do Rio de Janeiro. Atividade profissional: Hostess na empresa AIRBNB. Endereço físico para correspondência: Rua Vitória Régia, 14. CEP: 22753-034 - Rio de Janeiro - Rio de Janeiro (Brasil). Email: irmha@ hotmail.com

** Formação: Graduação em Turismo (bacharelado) pela Universidade de Marília, Especialização em Educação Ambiental pela Faculdade de Saúde Pública da Universidade de São Paulo, Mestrado em Desenvolvimento Regional e Meio Ambiente pela Universidade de Araraquara, Doutorado em Meio Ambiente pela Universidade do Estado do Rio de Janeiro. Atividade profissional: Professor Adjunto e Vice-diretor do Instituto de Geografia da Universidade do Estado do Rio de Janeiro. Endereço físico para correspondência: Av. Alberto Torres, 1019. CEP: 25964-002 - Teresópolis - Rio de Janeiro (Brasil). Email: rafael.fortunato@uerj.br
} 


\section{INTRODUÇÃO}

A cidade do Rio de Janeiro, para além dos atrativos turísticos mais tradicionais como o Cristo Redentor, Pão de Açúcar, Jardim Botânico, passou a oferecer visitas nas favelas.

Os percursos nas favelas, frequentemente, são comparados como uma espécie de "safári", pois quando os turistas entram nas favelas em jipes, um modo comum de fazer as visitas, eles tiram suas fotos e logo depois vão embora. Nesses casos, todo o dinheiro envolvido beneficia somente as agências de turismo (FORTUNATO, 2010).

No entanto, considera-se que quando os turistas interagem com o morador, é possível vivenciar o cotidiano da favela, gerar renda para o morador e mostrar para o turista que a mesma faz parte da memória da cidade. Nela, a cultura do Rio de Janeiro se cria e se transforma, pois a cidade é conhecida pelo senso comum como berço do samba, do funk e de várias outras manifestações de arte e cultura que possuem expressão nacional e internacional.

Neste artigo se faz uma análise exploratória das transformações ocorridas na favela do Vidigal, que se localiza entre os bairros de Ipanema e de São Conrado na zona sul do Rio de Janeiro, depois do aumento da atividade turística no local.

Buscou-se analisar o turismo na favela do Vidigal de forma abrangente visando identificar a maneira pela qual o mesmo estava sendo apropriado pela população local. Acredita-se que a importância deste estudo é mostrar que o turismo estava provocando diversas transformações no espaço. Ao identificar as mudanças pode-se pensar sobre as dinâmicas do território influenciado pelo desenvolvimento do turismo e propor novas formas de pensar a atividade.

No decorrer da pesquisa participou-se das festas realizadas nos albergues dentro do morro, trabalhou-se com a associação de moradores, participou-se de almoços familiares aos domingos e de churrascos nas lajes. Além da observação participante, buscou-se se inspirar, também, nos elementos do olhar etnográfico, procurando fazer uma descrição densa do lugar (GEERTZ, 1989). Trabalhou-se com entrevistas semiestruturadas aplicadas aos moradores e visitantes da favela e partiu-se da seguinte pergunta orientadora: o que você pensa sobre o turismo na favela? Além disso, fez-se o acompanhamento de reportagens de jornais e revistas sobre o Vidigal. Esta pesquisa foi 
realizada entre os anos de 2012 e 2016 e será apresentada da seguinte forma: no próximo item comenta-se sobre a favela carioca de forma sucinta, em seguida, se dá destaque ao turismo que se verificou estar ocorrendo na mesma e concluiu-se a análise fazendo um panorama de como o turismo estava transformando a favela do Vidigal.

\section{A FAVELA CARIOCA}

O poeta e cronista Olavo Bilac (1907) sintetiza a favela carioca da seguinte forma: "é uma cidade à parte", que nasceu nos cortiços do centro e era percebida como um espaço de contágio de doenças e do vício (SANTANA, 2009). Pereira Passos ${ }^{1}$, ao propor sua reforma urbana no Rio de Janeiro propunha sanear, civilizar a cidade e eliminar as favelas. No entanto, o número de favelas continuava crescendo (EDMUNDO, 1938).

Segundo dados do IBGE (Instituto Brasileiro de Geografia e Estatística), dos 11. 793.174 residentes na região metropolitana do Rio de Janeiro, 1.702 .073 de pessoas estavam morando em favelas (IBGE, 2010).

A cidade do Rio de Janeiro apresentou uma história de crescimento urbano marcado por grande número de favelas, nas quais existem fortes desigualdades das ofertas de infraestruturas e de serviços. Vetter e Massena (1982), analisando a cidade, identificaram em sua dinâmica uma matriz perversa de distribuição dos recursos urbanos, que direcionava os investimentos públicos direta ou indiretamente para as camadas já mais bem servidas e de alta renda.

No gráfico 1 se pode notar como a proporção das favelas vem crescendo em direção a Barra da Tijuca (zona oeste litorânea).

\footnotetext{
${ }^{1}$ Pereira Passos foi prefeito do Rio de Janeiro entre 1902 e 1906.
} 


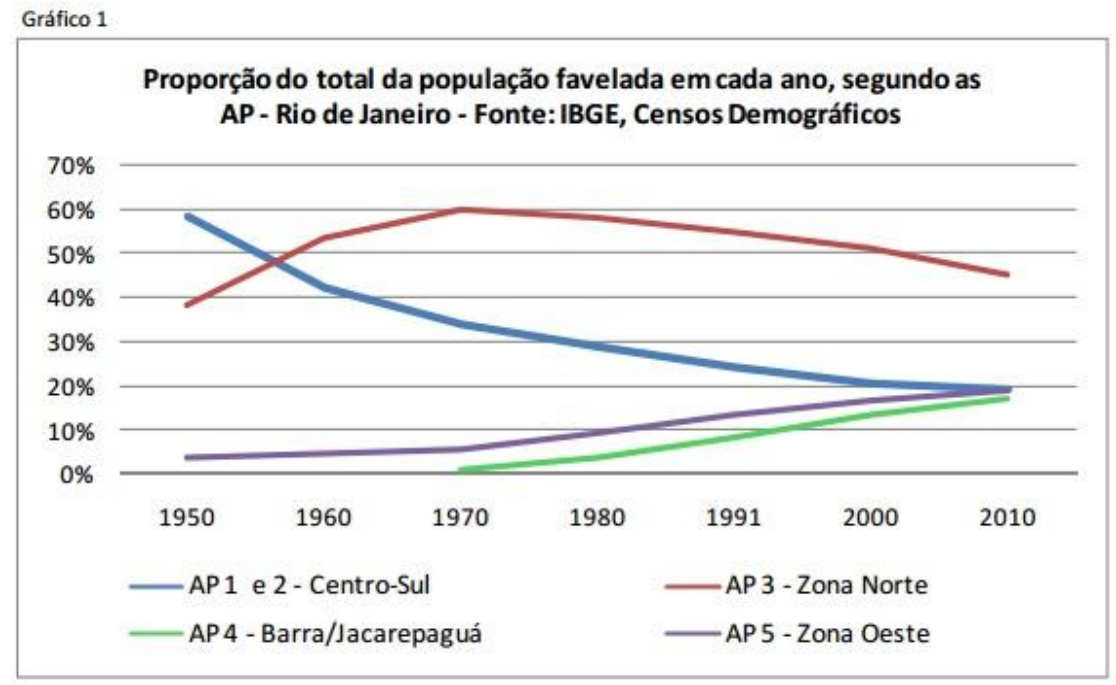

Nota: Para atenuar imprecisర̋es, os dados das AP 1, de pequena expressăo, foram agregados aos da AP 2 .

GRÁFICO 1 - PROPORÇÃO DO TOTAL DA POPULAÇÃO FAVELADA POR DÉCADA (1950-2010) NA CIDADE DO RIO DE JANEIRO

FONTE: IBGE, 2010.

Além da grande presença na zona norte, a zona oeste também passou a se tornar uma região com uma grande quantidade de favelas. Já existindo mais de 800 favelas no Rio de Janeiro (IBGE, 2014).

Pode-se afirmar que em complemento às dificuldades provocadas pela falta de infraestrutura, os moradores das favelas cariocas precisaram resistir para manter-se em seu território, principalmente aqueles que possuem vista para orla carioca. A luta contra a remoção sempre esteve presente na rotina dos moradores e esse espaço, com múltiplas facetas, passou a ganhar cada vez mais força no cenário turístico trazendo uma série de transformações, que serão apresentadas no decorrer deste artigo.

\section{A CONSTRUÇÃO DA FAVELA COMO DESTINO TURÍSTICO}

Michael Jackson sobe o Santa Marta (1996) e o filme Cidade de Deus (2003) são exibidos em vários lugares do mundo. A mídia constrói um imaginário sobre a favela e considera-se poder afirmar que a mesma é incorporada ao mercado turístico e torna-se uma espécie de segmento ou novo atrativo no campo do turismo. Urry (1992, p. 75) argumenta que: 


\begin{abstract}
$\mathrm{Na}$ sociedade de consumo contemporânea, os serviços especializam-se e segmentam-se na intenção de responder ao desejo de singularizarão e comunicação das diferenças. Com o turismo, não poderia ser diferente: o mercado organiza-se de maneira a atender gostos e expectativas os mais variados e, no processo, "inventa" o turismo dito alternativo, que transmuta em destino turístico localidades desprovidas dos atributos privilegiados no turismo da "era fordista".
\end{abstract}

É o caso da favela carioca. O turismo tem sido cada vez mais se segmentado com a intenção de chegar o mais próximo possível do que o turista/consumidor deseja. Com isso, são criados diversos tipos de segmentação como: turismo cultural, ecoturismo, turismo GLBTS e o turismo alternativo ou turismo de realidade, categorias, nas quais, o turismo nas favelas tem sido frequentemente incorporado por algumas agências de turismo (LAGE, 1992, p. 34).

Outra categoria, na qual o turismo em favelas pode ser incorporado, tem sido o chamado "turismo de experiência", que integra essa tendência propondo novas configurações aos produtos turísticos. Mencione-se que esse segmento ou forma de fazer turismo surgiu a partir do livro "Sociedade dos Sonhos" de Rolf Jensen (1999), que é a tradução do termo inglês "The Dream Society”, que ainda não conta com uma ampla bibliografia sobre o conceito, no entanto, já está sendo utilizada como metodologia por empresas, inclusive as turísticas, para propagar e formatar novos produtos e serviços que terão como marca a diferenciação (JENSEN, $1999^{2}$ apud BORDAS, 2003).

As ideias de Jensen $(1999)^{3}$ apresentadas por Bordas (2003) sinalizam uma nova forma de pensar a atividade turística, mas não só a atividade, também uma nova forma de pensar nas necessidades da sociedade, que, cada vez mais se alinham em encontrar o melhor equilíbrio entre os aspectos racionais e emocionais do ser humano.

De acordo com Freire-Medeiros (2009, p. 40) "A rotina das favelas cariocas sempre atraiu turistas estrangeiros em meio suas casas amontoadas, simplicidade e vielas. Na Rio-92 iniciou um tipo de circuito, que teve a Rocinha como percussora". Constata-se que as favelas estão incluídas em diversos guias turísticos que apresentam os atrativos turísticos do município.

\footnotetext{
${ }^{2}$ JENSEN, R. The Dream Society. How the coming shift from information to imagination will transform your business. New York: McGraw-Hill, 1999.

3 Idem.
} 
Para Freire-Medeiros (2008) os moradores veem a presença do turista de forma positiva. Ressalta que os visitantes podem mudar sua visão sobre favela e quebrar os estereótipos de ser um lugar somente com lixo, esgoto a céu aberto, fiação elétrica sem proteção e um lugar violento. Tal fato pode ser constatado em uma das falas de moradores apresentada por Freire-Medeiros (2010, p. 39):

\begin{abstract}
A mim [a presença dos turistas] não incomoda. Até faz bem para comunidade, ajuda a tirar aquela ideia de que é um lugar violento. Eu tenho amigos que, quando falo que moro na Rocinha, dizem que não vão lá nunca, pois teria tiroteio todo dia, toda hora. Então, com o turismo tira essa impressão de que é só violência.
\end{abstract}

Ainda de acordo com a autora, que concentrou suas pesquisas na favela da Rocinha, é possível constatar que alguns líderes comunitários são a favor do turismo, porém não concordam com o modo que a atividade é desenvolvida e comercializada. Verificou-se que os moradores demonstraram ter conhecimento sobre a atividade turística nas favelas como uma forma lucrativa e de inserção cultural de ambos os lados, saindo de um turismo feito apenas por agências, apostando, por exemplo, no turismo solidário, como no caso da pesquisa realizada por Fortunato (2013) no Complexo do Alemão e em outras favelas do Rio de Janeiro.

O turismo solidário é "um fenômeno social de múltiplas determinações, que, por meio de relações interpessoais solidárias, sinaliza possibilidades de transformação pessoal e social e, eventualmente, envolve ações voluntárias para melhoria dos problemas socioambientais" (FORTUNATO, 2014, p. 90).

Mesmo os que não trabalhavam com a atividade não se mostraram avessos à presença do visitante, sendo hospitaleiros e tentando manter contato, mas isso sendo dificultado pela língua (FREIRE-MEDEIROS, 2009). Neste sentindo, mostra-se que a receptividade dos moradores é positiva, fato que dialoga com a teoria de Camargo (2004), que propõe a hospitalidade doméstica como um ato voluntário, utilizando o termo "receber doméstico", categoria que trata das questões "sociológicas, psicológicas e antropológicas da hospitalidade" (CAMARGO, 2004, p. 55). Acredita-se poder justificar essa receptividade a partir do seguinte trecho apresentado por Freire-Medeiros (2010, p. 43-44): 


\begin{abstract}
Não, não sou de cobrar a ninguém”, respondeu, empregada doméstica de 49 anos. E justificou: "É algo que se faz por amor e o amor não tem preço. Faria o passeio com todo gosto, levaria para passear, para conhecer a Rocinha, faria com o maior prazer." M., de 28 anos, que trabalha como forneiro, concorda: "Eu não cobraria nada. Faria na maior boa vontade, sem cobrar nada. Os turistas [mexicanos] que vieram para cá uma vez me ofereceram dinheiro e eu disse 'não quero, não quero'. E eu fiquei 'amarradão' dos caras conhecerem a comunidade onde eu fui criado, onde eu vivo... As agências cobram? Eu não sei... então eu não posso dizer se está caro, se está barato. Eles devem ter os gastos deles também. Eu faria de graça, sem cobrar nada.
\end{abstract}

Percebeu-se, portanto, certa hospitalidade dos moradores de favelas, o que poderia remeter para as discussões sobre o "dom da dádiva" (MOUSS, 1974) que favorece o encontro e as trocas de saberes. Esta, portanto, é uma outra forma de entender o turismo na favela. Fortunato (2013) destaca a relevância dos encontros entre turistas e moradores de favelas como uma forma de alargamento da percepção de mundo.

Com quase todas as comunidades da zona sul pacificadas, alguns turistas trocaram os famosos hotéis da Orla por albergues com belas paisagens nas favelas, como se observou na pesquisa de campo que deu origem a este artigo. A experiência de vivenciar a rotina de uma favela e a vista do alto dos morros tornam a viagem diferenciada. Para esses grupos, parece valer mais a pena do que o conforto dos luxuosos hotéis na Orla.

Ao contrário de hotéis que oferecem muito conforto, os morros oferecem experiências diferenciadas e paisagens panorâmicas a preços mais acessíveis. Turistas que já se hospedaram, voltam ou indicam para amigos. Como os outros meios de hospedagem da cidade, os albergues em favelas possuem um alto índice de ocupação na alta estação.

Pensando nos grandes eventos sediados na cidade, e na cidade com um fluxo maior de turistas, verificou-se que alguns moradores das favelas cariocas construíram albergues, pousadas comunitárias e passaram a trabalhar com o conceito "cama e café" para abrigar parte dessa demanda.

Constatou-se também, que além de oferecer hospedagem, muitos eventos e festas passaram a acontecer nas lajes. Muitos moradores dos morros cariocas resolveram apostar neste mercado e alguns roteiros chamam a atenção dos turistas, como um tour na favela da Rocinha, a feijoada com samba na Mangueira e a visita panorâmica por um elevador no morro Dona Marta: 


\begin{abstract}
A complexidade dos tours de realidade - quer sociais quer sombrios deve-se, sobretudo, ao fato de seu objeto de consumo não ser algo óbvio e tangível. Articulam-se, nos reality tours, dois domínios: dinheiro e emoções - cuja superposição a moralidade ocidental define como incongruente e agramatical. Não por acaso, a prática desse tipo de turismo está sempre envolta em calorosos debates, mormente aquele que se dá em torno da pertinência ética de fazer-se da miséria alheia mercadoria. Em geral, seus opositores acusam-nos de motivar sentimentos e atitudes voyeuristas diante da pobreza e do sofrimento. Argumento que a favela elaborada e vendida como atração turística condensa as premissas dos dois tipos de tours de realidade: ao mesmo tempo em que permite engajamento altruísta e politicamente correto diante da paisagem social, motiva um sentimento de aventura e de deslumbramento diante da paisagem física. Mas não apenas: como hipótese complementar, sugiro que o tour de favela seja igualmente tributário do fenômeno de circulação e consumo, em nível global, da favela como uma marca que condensa predicados contraditórios. (FREIREMEDEIROS, 2008, p. 4).
\end{abstract}

O turismo na favela pode ser percebido como um elemento de valorização local e a promoção desse destino, a "pobreza turística" que, por um lado beneficia o mercado local, muda as imagens midiáticas e modifica o que era feio para exótico, por outro lado, aumenta a disputa pelo território e a especulação imobiliária muda toda forma econômica, social e cultural, fatos que serão ilustrados com análises do caso do turismo no Morro do Vidigal.

A ideia de um turismo responsável e solidário representa novas utopias para a prática das atividades turísticas nas favelas. Para realizar esse potencial transformador, as iniciativas de turismo nas favelas precisam estabelecer uma estratégia sólida de comercialização. O intuito é de garantir sua viabilidade econômica sem que isso signifique a perda dos valores que sustentam e conferem uma identidade diferenciada ao roteiro. Priorizar o trabalho de divulgação junto a grupos sociais sensíveis à temática socioambiental pode representar um importante avanço no sentido de vincular o turismo solidário como opção de lazer prioritária desses grupos (FORTUNATO, 2013).

\title{
4 O TURISMO SOBE O VIDIGAL: UMA ANÁLISE EXPLORATÓRIA
}

O morro do Vidigal localiza-se ao lado do morro Dois Irmãos e das praias de Ipanema, Leblon e São Conrado. Por ter sua localização privilegiada, sua história está marcada por tentativas de remoções e resistência. A população estimada é de 10.372 habitantes (INSTITUTO PEREIRA PASSOS, 2014). 
O processo de "turistificação" do Vidigal aconteceu lentamente, a partir do fim da guerra entre facções e a entrada da UPP (Unidade de Polícia Pacificadora). Com a redução dos confrontos armados, os turistas começaram a subir o morro e descobrir um lugar com uma bela vista (FIGURA 1) e grandes atrativos culturais.



O Vidigal enquanto produto estava sendo vendido por cinco agências de turismo receptivo do Rio de Janeiro e contava com alguns monitores locais. Vale ressaltar que todas as agências que estavam vendendo o Vidigal eram agências de fora do morro.

No entanto, observou-se que o boom do turismo no Vidigal fez com que os empreendedores locais começassem a se organizar para que fosse possível fazer parte do processo turístico seguindo as concepções do turismo de base local. A partir desse momento se iniciou um processo de transformação no morro do Vidigal. Para facilitar o entendimento das dimensões envolvidas nas transformações que passaram a ocorrer no Vidigal, se faz uso de algumas categorias de análises.

\subsection{A INFLUÊNCIA DA MÍDIA}

Constata-se que as mídias (filmes, novelas, programas de tv, jornais, revistas e etc.) têm incentivado a atividade turística no Vidigal, provocando aumento do fluxo e o 
interesse turístico pela favela. A mídia vem construindo uma "nova favela", na visão de Freire-Medeiros (2004) ela constrói uma espécie de "favela mítica":

Essa cultura de uma favela mítica é utilizada nas campanhas publicitárias de marcas e produtos os mais variados; por sua vez, os produtos brasileiros, quando comercializados internacionalmente, também aderem à marca favela: A onda atual de 'favela chic' tornou até a mais humilde mercadoria brasileira, a sandália de borracha, em um objeto de fetiche" (FREIRE-MEDEIROS, 2004, p. 17).

No jornal "O Globo" se fala de uma "favela chique" ${ }^{4}$. Em um programa apresentado por Fernando Gabeira na emissora "Globo News" 5 revela-se que "estrangeiros e ricos descobrem o morro do Vidigal e causam uma disputa de território". A rede Bandeirantes de televisão foca nas festas que ocorrem no Vidigal e seu consumo por um público de classe média e alta. Mostra, também, que o morador não possui acesso as tais festas.

Observou-se que o aumento de informações sobre o Vidigal foi incessante depois da pacificação. Foi tão crescente a produção de informações que algumas pessoas passaram a "admirar" o Vidigal e falar sobre ele mesmo sem nunca ter feito uma visita.

Não se pode deixar de ressaltar a fala de uma moradora durante o primeiro fórum de debates em que os pesquisadores tiveram oportunidade de participar, que explicitou criticamente o papel da mídia "enquanto na novela das nove a atriz Bruna Marquezine subia o morro para uma festa no Vidigal, estava acontecendo um confronto entre policiais e traficantes na região do quatorze aqui no morro". A mídia fantasia o morro e constrói uma favela imaginária, enquanto muitos moradores e pesquisadores insistem em mostrar uma favela mais próxima da realidade. No entanto, a exposição midiática contribuiu com o aumento do interesse pela favela e estimulou a atividade turística.

\footnotetext{
${ }^{4}$ Disponível em:

<http://oglobo.globo.com/rio/vidigal-atrai-moradores-ilustres-ganha-status-de-favela-chique-8412639>. Acesso em: 20/03/2015.

${ }^{5}$ Disponível em:

<http:/globotv.globo.com/globo-news/fernando-gabeira/t/ultimos-programas/v/fernando-gabeiraestrangeiros-e-ricos-descobrem-morro-do-vidigal-no-rj/3443170/>. Acesso em: 20/03/2015.
} 
O desafio é equilibrar o avanço do turismo no seu território e a permanência dos antigos moradores no morro, pois houve um aumento nos preços dos imóveis, iniciando uma especulação imobiliária.

\title{
4.2 ESPECULAÇÃO IMOBILIÁRIA
}

No decorrer do trabalho, se tratou sobre grandes problemas que acontecem em todas as favelas do Rio de Janeiro: a luta por moradia e o medo da remoção sendo constantes para os moradores das áreas mais pobres. Ao longo do tempo, os moradores da favela do Vidigal vêm lutando pelo direito de moradia em seu local. Mencione-se que a ameaça não está relacionada apenas a questão das remoções, mas também a especulação imobiliária e ao aumento do custo de vida na favela.

No sítio eletrônico da revista Carta Capital (2014), tem-se como observar um relato sobre o processo de especulação imobiliária na favela carioca:

\begin{abstract}
A passagem escura e estreita leva à casa de Glenda Melo. Ela vive com os pais e o irmão em 35 metros quadrados. Sala, cozinha, banheiro, dois quartos e uma pequena área de entrada. Em nenhum dos cômodos é possível dar mais que dois passos. A geladeira fica rente à porta, dificultando a passagem. $\mathrm{O}$ banheiro mal dá para uma pessoa tomar banho em pé. Da janela, só é possível ver um varal com a roupa dos vizinhos. Mas Glenda tem orgulho do seu lar e se sente bem nele. Só os pratos sujos a fazem ter um pouco de vergonha. "Eu não tive tempo de arrumar a casa", se desculpa a moça, rindo, enquanto oferece um lugar no sofá. Há três meses, outro convidado esteve sentado nesse mesmo sofá na apertada sala de estar, onde não entra luz natural direta, pois a janela gradeada dá para um pátio interno. O homem de São Paulo percorreu os corredores da favela, bateu de porta em porta. Ele olhou através das barras diretamente para a sala de Glenda, depois ofereceu 140 mil reais à mãe dela pela compra da casa (WELLE, 2014).
\end{abstract}

Neste contexto, se pôde constatar que a especulação imobiliária chegou ao Vidigal e os moradores recebem cada vez mais propostas para venderem suas casas. Casas com vista para a orla da zona sul adquiriram um valor que os moradores não haviam imaginado.

Um membro da Associação dos Moradores da Vila do Vidigal (AMVV) disse que estava ocorrendo uma "remoção Branca" e comentou que "estão descobrindo o Vidigal como um lugar para bons negócios, um imóvel que custava 30 mil por volta de 2004/2005, hoje em 2015 não vale menos que R\$ 350 mil”, afirmou. 
O morador destacou que estava orientando os antigos moradores a não venderem barato seus imóveis nem se mudarem para muito longe, pois isso provocaria uma mudança de hábitos muito grande para quem estava acostumado com a comunidade. Um corretor de imóveis no Vidigal ratificou a fala do morador ao afirmar que "a maioria dos moradores se arrepende quando vende seu imóvel e se muda da favela" (FIGURA 2).

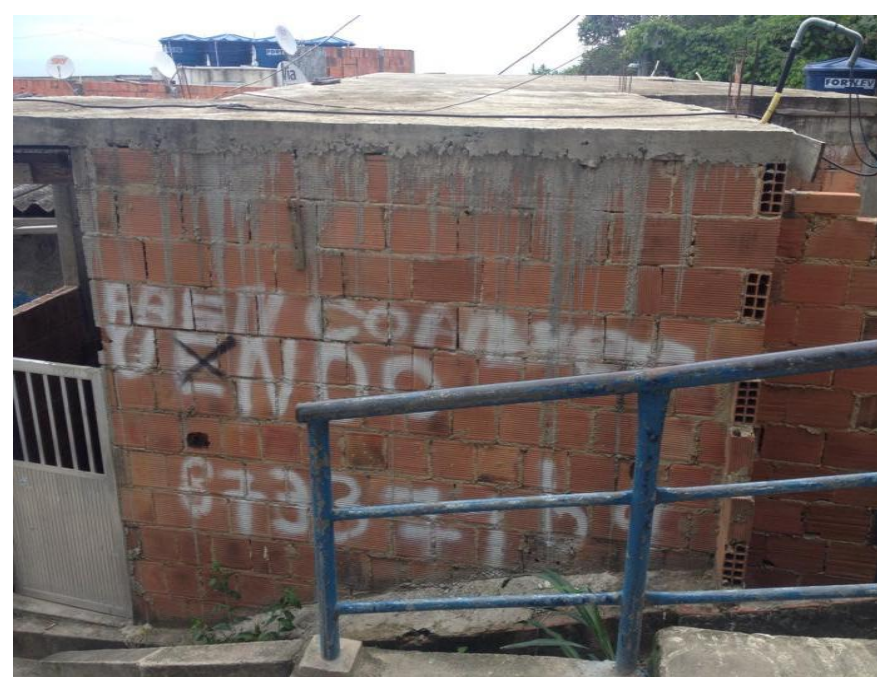

FIGURA 2 - CASAS A VENDA NO MIRANTE DO ARVRÃO FONTE: Miranda (2015).

Identificou-se que mesmo com a grande procura imobiliária, o Vidigal ainda estava sofrendo com a precariedade na infraestrutura, no saneamento básico e na coleta de lixo. A Associação dos Moradores estava reunindo-se com a prefeitura e reivindicando investimentos do Programa de Aceleração do Crescimento (PAC), do Governo Federal, e lutando por um planejamento urbano, já que as ruas são estreitas e o excesso de pessoas torna difícil a acessibilidade. Artistas plásticos e empresários já compraram casas no morro. Diversos outros produtores culturais, artistas e arquitetos se tornaram adeptos ao lugar, como o músico pernambucano Otto. Havendo ainda aqueles que nasceram no Vidigal e não pretendiam sair, como a atriz Roberta Rodrigues.

O proprietário do Hostel "Alto Vidigal” (o hostel mais procurado para as festas eletrônicas) ressaltou que "valorizou muito sim, mas isso pode ser apenas especulação e depois de um tempo os valores acabam caindo novamente. $\mathrm{O}$ crescimento muito rápido normalmente não é saudável e o povo é que sofre com isso". 
Tendo em vista esse cenário, inicia-se, pelo moradores, a discussão do que tem sido chamado de gentrificação. A palavra gentrificação (do inglês gentrification) pode ser entendida como o processo de mudança imobiliária nos perfis residenciais e padrões culturais, seja em um bairro, cidade ou região (SMITH, 2006). Este processo envolve necessariamente a troca de um "grupo" por outro com maior poder aquisitivo em um determinado espaço e que passa a ser visto como mais qualificado para ocupá-lo (SMITH, 2006).

Segundo Smith (2006) o termo gentrificação é derivado de um neologismo criado pela socióloga britânica Ruth Glass, em 1963, mencionando que ela aborda as mudanças urbanas em Londres e faz referência ao "aburguesamento" do centro da cidade, para isso usa o termo irônico "gentry", que pode ser traduzido como "bemnascido".

O Vidigal, assim se configura nesse processo, que pode resultar na descaracterização da favela. Essa nova reorganização espacial preocupa justamente os que não estão dentro desse "novo grupo", pois esses são obrigados a sair de suas casas devido aos altos custos dos serviços e despesas. Dessa forma, o espaço se torna um mecanismo de poder coercivo.

\footnotetext{
É importante lembrar que ao mesmo tempo que o espaço é produto e meio da ação social, é também instrumental e um mecanismo de poder que simultaneamente produz uma hierarquia de lugares. Portanto, o espaço é fundamental para o processo de acumulação e de reacomodação de poder e deve ser colocado como prioridade nos estudos sobre gentrificação (GRAFFNEY, 2010, p. 12).
}

A construção de vida e luta, não somente por um espaço, mas por espaço vivido, torna-se espaço de "resistência e sobrevivência" como assinalado por Corrêa (1989) e palco de lutas no Vidigal, visto que o morador precisa sobreviver à especulação imobiliária. O primeiro fórum de debates entre a associação de moradores, pesquisadores e convidados, teve como pauta principal "Especulação Imobiliária e os altos preços na favela".

No fórum se chamou atenção para a questão da gentrificação e foram discutidas formas de conduzir e resistir a esse processo. Uma das participantes do fórum e uma das mais antigas moradoras disse: “construa por necessidade e não por ganância”. Assim, se 
teve como constatar que o processo de gentrificação no Vidigal estava se acentuando fortemente e promovendo profundas transformações culturais, espaciais e territoriais.

\subsection{TRANSFORMAÇÕES CULTURAIS}

Observou-se que as transformações culturais estavam cada vez mais presentes na vida dos moradores do Vidigal. O baile funk no mirante do Arvrão, o pagode na praça principal e as rodas de rap dando lugar para as festas marcadas pela música eletrônica, que estavam acontecendo dentro dos hostels e por um preço muito elevado. Um trecho de reportagem da revista "Carta Capital" de 2013 expõe as transformações culturais que foram vivenciadas em algumas favelas cariocas:

Poderia ser um réveillon em Búzios: gente jovem, produzida, moças com roupas leves, bijuterias que valorizam o bronzeado e combinam com a maquiagem nude. Mas estamos no Pavão-Pavãozinho, favela da zona sul carioca acostumada até há bem pouco tempo ao espetáculo macabro dos enfrentamentos entre policiais e traficantes (GOMBATA, 2013)

Tal descrição coube perfeitamente para o Vidigal. A moda do momento estava sendo a das festas nos principais morros da zona sul carioca. Os ingressos custando entre 30 a 120 reais, em geral, inacessíveis aos moradores do morro. "A pacificação dos morros fez com que a 'playboyzada' começasse a frequentar as oficinas de escolas de samba nas comunidades", explicou um produtor cultural que organizava festas em boates da zona sul.

As festas estavam acontecendo, em sua maioria, onde antes ocorriam os bailes funk e traziam sons variados como hip-hop, soul music, samba e jazz. Apesar da mudança de público, as festas estavam causando aos moradores da comunidade os mesmos transtornos de antes: a privação do sono por um som ensurdecedor até o amanhecer. Em algumas comunidades, o barulho estava levando moradores a protestar e a exigir que se cumprisse a lei do silêncio (com poucos resultados). No Vidigal, por exemplo, as festas da "Oficina do Jô", frequentadas por estrangeiros e "cariocas do asfalto", não acabavam antes das cinco da manhã (GOMBATA, 2013).

Sobre esses fatos, uma moradora de 29 anos protestou que "não pode ter baile funk, mas pode ter festas como essas", referindo-se as festas de música eletrônica e continuou mencionado que "a justificativa de o problema ser o som alto do baile funk é 
mentira, a diferença é que, como essas festas (músicas eletrônicas) são voltadas para o público mais elitizado, tudo é permitido". Considerou-se que tal comentário revelou mais um conflito provocado pelo turismo no Vidigal.

Uma visitante e frequentadora das festas nos morros ironizou: "O barulho que reclamam do funk é outro. Para eles (UPP, governo) não é conveniente ter baile funk onde a comunidade reafirma seu espaço. Me pergunto se essa pacificação das UPPs é para quem mora aqui ou para a gente lá de baixo".

Por outro lado, algumas festas estavam gerando renda para a comunidade local. Um vendedor ambulante que trabalhava com água e chicletes na subida da Rua Saint Roman, um dos acessos ao Vidigal, dava boas-vindas aos novos frequentadores do morro onde estava morando desde 1994 e disse que "essas festas são ótimas, trazem novas pessoas, novas amizades e não têm violência".

Na subida do Vidigal, um boteco tradicional virou um restaurante japonês. As marcas mais populares de cerveja cederam espaço para as importadas. O estabelecimento simbolizava a mudança no perfil da clientela: saíram os moradores, entraram os "turistas" e visitantes. Passou a existir também os novos estabelecimentos de novos moradores estrangeiros, como é o caso do bar Las Empanadas, em que o proprietário é argentino e mora no Vidigal.

O novo bar estava sendo um ponto de parada na subida do Vidigal. Para aqueles que ainda enfrentariam a pista de dança da Oficina do Jô, o local havia virado sinônimo de “esquenta". Para quem não podia pagar R\$ 40 reais de entrada e R 8 reais por uma cerveja longneck, a noite acabava por ali, com uma latinha na mão e ouvidos atentos ao som que saía das festas.

Alguns eventos estavam oferecendo lotes de ingresso com preço acessível aos moradores, mas eram pouco divulgados. "Nem temos notícias desses ingressos mais baratos", reclamou uma moradora. "Uma festa que custa 40 reais é feita justamente para as pessoas da comunidade não participarem, é uma discriminação contra o pessoal daqui, no nosso próprio espaço". Sobre o possível ressentimento dos moradores, uma produtora cultural afirmou:

Já pensei muito sobre isso, mas sempre falamos com a associação dos moradores, convidamos os vizinhos. Em algumas festas, quando chegam e dizem que são da comunidade, tentamos fazer um preço mais em conta ou damos um ingresso. Tem de haver flexibilidade, pois, teoricamente, nós invadimos o espaço deles. 
Em entrevista informal, Danilo Cymrot, estudioso da marginalização do funk ressaltou que a onda de festas em morros pacificados revelava um movimento sutil da política das UPPs. Para ele, “essa moda deixa clara a invasão do asfalto nas áreas de favela, das quais a classe média já se apropriou para lazer. Você permite que os jovens do asfalto tenham o que os jovens da comunidade tinham e não têm mais", reflete (GOMBATA, 2013).

E continuou mencionando que "para mim, só reforça a tese de que a criminalização do funk é um processo seletivo que esconde a criminalização da população identificada por esse estilo de música: negra, jovem e favelada”. Considerouse então poder afirmar que essas transformações não estavam ocorrendo sem uma reação dos moradores, que procuraram se mobilizar.

\subsection{MOBILIZAÇÃO SOCIAL}

Percebeu-se que o Albergue da comunidade estava sendo um exemplo de mobilização social em torno do turismo. Isso, pois os albergues trabalham com hospedagem domiciliar, visto que se verificou haver uma grande procura por parte dos turistas. Os moradores do morro arrumavam um ou dois quartos e recebiam alguns turistas com um preço mais acessível. Duas famílias já haviam recebido turistas e a troca de experiência havia obtido um resultado positivo, segundo os mesmos.

Além do albergue da comunidade, no mês de abril, a comunidade e a associação de moradores organizaram o primeiro fala Vidigal (FIGURA 3).

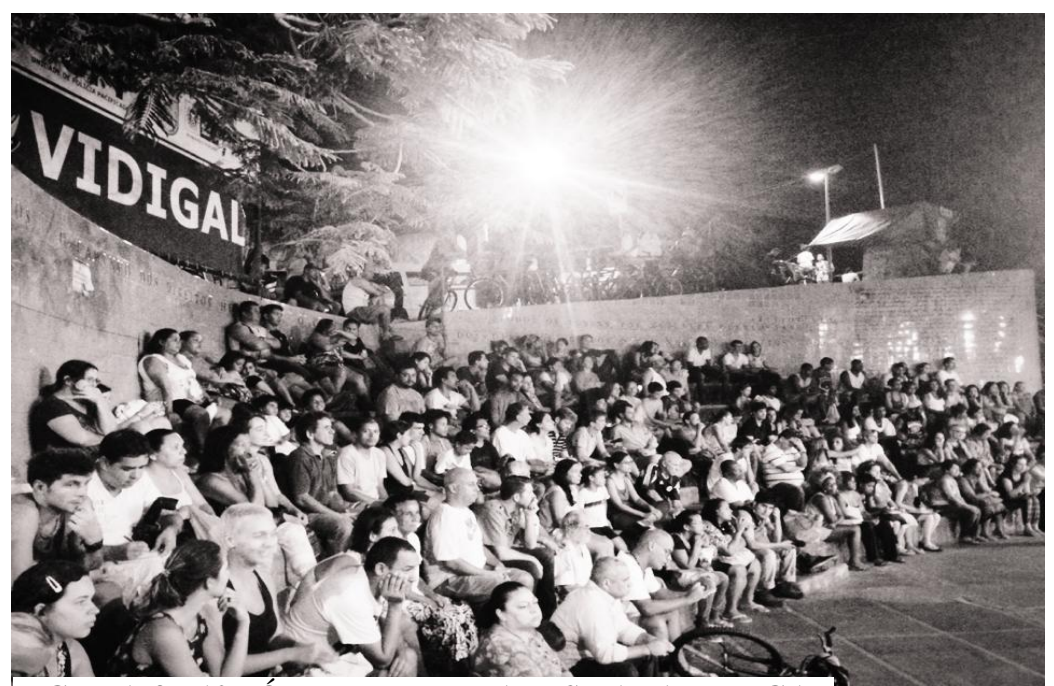

FIGURA 3 - $1^{\circ}$ FÓRUM DE DEBATES FALA VIDIGAL

FONTE: Miranda (2013). 
Os encontros ocorreram quinzenalmente. A cada fórum os moradores escolhiam seus temas para discussão. No dia em que os presentes pesquisadores participaram, havia cerca de 120 pessoas e o tema principal foi o processo de gentrificação. Questionavam se a forma com que vinha acontecendo era negativa ou positiva, entre outras discussões. Outro tema abordado foi a entrada de novos empresários na favela.

\begin{abstract}
A pessoa tem que ter consciência que a casa dela tem um valor humano muito grande. Tem que pensar se vale à pena sair daqui para morar em outro lugar por R\$200.000,00. Você não muda só de endereço, muda de hábitos, muda de tempo. Depois fica em depressão porque as pessoas que conviviam perto de você vão morar distante. Então você tem que começar a pensar por este lado. Eu costumo dizer que a favela é o lado mais original do Rio de Janeiro. Onde as pessoas vivem muito próximas. O vizinho que a gente pede um açúcar, a solidariedade que é fantástica - você está passando mal eu te levo no Miguel Couto. Tudo isso tem que ser pesado, posto na ponta do lápis, pensar se vale a pena vender a sua casa e ir morar num lugar bem distante (MORADOR LOCAL, 2013).
\end{abstract}

O diretor cultural e social da associação, durante a pesquisa, explicou que "o futuro do Vidigal significava também olhar para o passado; o Vidigal dos anos 80 era muito bom" e completou "nós queremos reanimar essa identidade, dar uma olhada para essa origem".

Segundo a associação dos moradores, era necessário trabalhar para que a juventude da comunidade se apropriasse da vida cultural. A associação, juntamente com algumas ONGs, estava planejando eventos com este mesmo objetivo, como, por exemplo, a Feira de Artesões do Vidigal, com a proposta de trazer visibilidade aos artesões do morro e favorecer o comércio local. A comunidade do Vidigal estava se mobilizando e fazendo uso do turismo para melhorar sua qualidade de vida.

\title{
5 CONSIDERAÇÕES FINAIS
}

Constatou-se que o turismo transformou radicalmente a favela do Vidigal e tal transformação ocorrendo de forma cada vez mais rápida. Fato que dificultou a conclusão do presente trabalho. A cada subida novas informações surgiam e a mídia continuava veiculando novidades frequentemente. 
Destaca-se, como resultado constatado desta pesquisa exploratória, a organização de fóruns populares, a construção de pousadas comunitárias, a questão da contribuição do turismo para os moradores de favelas e reflexões sobre as possibilidades do turismo minimizar os problemas do processo da gentrificação e promover o desenvolvimento a partir dos valores locais.

Pondera-se poder afirmar que o turismo acentuou a lógica do mercado no Vidigal, produzindo novos territórios e mudanças nas relações de poder. Mais uma vez a reflexão sobre segregação apareceu com força na história das favelas. No entanto, dessa vez, a segregação estava ocorrendo no interior da mesma, travestida por uma espécie de "ideário hipster" 6 e fortalecida pelo velho desejo dos ricos de se apropriar da vista da favela para as praias da zona sul carioca.

Considerou-se que o turismo na favela estava possuindo forças ambivalentes, pois por um lado passou a produzir sérios problemas, por outro lado, a crise provocada pelos problemas passou a apontar para caminhos de superação e fortalecimento da comunidade.

Averiguou-se que os moradores do Vidigal passaram a refletir sobre as transformações do espaço e começaram a planejar a atividade turística. Não é possível dizer que os moradores estivessem passivos, apenas sofrendo com o processo de gentrificação e turistificação do território, pois passaram a (re) negociar os significados do turismo no morro e estavam buscando um turismo mais solidário, com inclusão social, e capaz de revelar as contradições presentes nas relações entre "asfalto" e favela.

\section{REFERÊNCIAS}

BORDAS, E. Hacia el turismo de la sociedade de ensueño: nuevas necessidades de mercado. Universidade Aberta de Catalunã, 2007. Disponível em: <http://www.uoc.edu/dt/20219/>. Acessado em: 29/12/2016.

CAMARGO, L. Hospitalidade. São Paulo: Aleph Ltda, 2004.

\footnotetext{
6 Indivíduos de classe média que valorizam um estilo de vida "sustentável", são considerados "descolados" e estão sendo responsáveis por processos de gentrificação em áreas como: Williamsburg no Brooklyn-NY. Ver mais em: <http://www.archdaily.com.br/br/758003/gentrificacao-os-perigos-daeconomia-urbana-hipster>.
} 
CEZAR, P. B. Evolução da população de favelas na cidade do Rio de Janeiro: uma reflexão sobre os dados mais recentes. Coleção Estudos Cariocas, n. 20120501, 2012.

CORRÊA, R. L. O espaço Urbano. São Paulo: Àtica, 1989.

EDMUNDO, L. O Rio de Janeiro do meu tempo. Rio de Janeiro: Imprensa Nacional, 1938.

FORTUNATO, R. Encontros no campo do turismo solidário do Vale do Jequitinhonha (Minas Gerais, Brasil). Turismo e Sociedade, v. 6, n. 1, 2013, p 104 -123.

FORTUNATO, R; CASTRO, E. Turismo em favelas cariocas: potencialidades de práticas de Educação Ambiental não formal para superação de problemas socioambientais locais. Revista de educação ambiental, v. 15, n. 2, 2010, p. 20.

FORTUNATO, R. Turismo solidário: em busca de um conceito. In: MARAFON, G; SOTRATTI, M; FACCIOLI, M. (Orgs). Turismo e Território no Brasil e na Itália: novas perspectivas, novos desafios. Rio de Janeiro: Eduerj, 2014, p. 90.

FREIRE-MEDEIROS, B. A favela que se vê e que se vende: reflexões e polêmicas em torno de um destino turístico. Revista Brasileira de Ciências Sociais, v. 22, 2008, p. 9.

Gringo na laje: produção, circulação e consumo da favela turística. Rio de Janeiro: FGV, 2009.

Entre tapas e beijos: a favela turística na perspectiva de seus moradores; Brasília: Sociedade e estado. v. 25, n. 1, 2010.

GEERTZ, C. A Interpretação das Culturas. Rio de Janeiro: LTC, 1989.

GOMBATA, M. O Asfalto invade o morro. Revista Carta Capital, 2013. Disponível em: <http://www.cartacapital.com.br/sociedade/o-asfalto-invade-o-morro>.

Acesso em: 29/12/2016.

GRAFFNEY, C. Mega-events and socio-spatial dynamics in Rio de Janeiro, Journal of Latin American Geography, v. 9, n. 1, 2010, p. 7-29. Disponível em: $<$ http://1mundoreal.org/wp-content/uploads/2009/09/Chris-Gaffney-2010-Mega-EventsRio-de-Janeiro.pdf>. Acesso em: 05/01/2017.

IBGE. Instituto Brasileiro de Geografia e Estatística. Disponível em: <http://www.ibge.gov.br/home/presidencia/noticias/29092003estatisticasecxxhtml.shtm >. Acesso em: 12/06/2015.

IBGE. Instituto Brasileiro de Geografia e Estatística. Censo de 2010. Disponível em: <http://www.ibge.gov.br/home/estatistica/populacao/censo2010/aglomerados_subnorma is_informacoes_territoriais/default_informacoes_territoriais.shtm $>$. Acesso em: 29/12/2016. 
INSTITUTO PEREIRA PASSOS, Instituto Municipal de Urbanismo Pereira Passos IPP. Disponível em: <http://www.rio.rj.gov.br/web/arquivogeral/linhadotempo>. Acesso em: 28/08/2015.

LAGE, B. H. G; Economia do turismo. Atlas, 1992. p. 32.

MAUSS, M. Sociologia e antropologia. São Paulo: Cosac \& Naify, 2003.

O GLOBO. Vidigal atrai moradores ilustres e ganha status de favela chique. Disponível em: <http://oglobo.globo.com/rio/vidigal-atrai-moradores-ilustres-ganhastatus-de-favela-chique-8412639>. Acesso em: 20/03/2015.

O GLOBO. Estrangeiro e ricos descobrem o morro do Vidigal. Disponível em: $<$ http://globotv.globo.com/globo-news/fernando-gabeira/t/ultimosprogramas/v/fernando-gabeira-estrangeiros-e-ricos-descobrem-morro-do-vidigal-norj/3443170/>. Acesso em: 20/03/2015.

SANTANA, J. R. A. A modernização do Rio de Janeiro nas obras de Olavo Bilac (1890-1908). Dissertação de Mestrado: Universidade Federal da Bahia, 2013.

SMITH, N. A gentrificação generalizada: de uma anomalia local à "regeneração" urbana como estratégia urbana global. In: Bidou-Zachariasen, C. (ed.). De volta à cidade. Dos processos de gentrificação às políticas de « revitalização » dos centros urbanos. São Paulo: Annablume, 2006.

WELLE, D. Gentrificação no Vidigal pressiona preços de imóveis. Carta Capital, 2014. Disponível em: <http://www.cartacapital.com.br/sociedade/gentrificacao-chegaao-vidigal-e-pressiona-precos-dos-imoveis-8227.html >. Acessado em 29/12/2016

URRY, J. O olhar do Turista. Studio Nobel, 1992.

VETTER, D.; MASSENA, R. Quem se apropria dos benefícios líquidos dos investimentos do Estado em infra-estrutura urbana? Uma teoria de causação circular. In: MACHADO da SILVA, L. (Org.) Tópicos sobre o uso da terra. Rio de Janeiro: Zahar, 1982, p. 49-78. 95 p.

Recebido em: 01-07-2016.

Aprovado em: 31-07-2016. 